\title{
Sweet Potato Canopy Morphology: Leaf Distribution
}

\author{
Zana C. Somda and Stanley J. Kays \\ Department of Horticulture, University of Georgia, Athens, GA 30602 \\ Additional index words. Ipomoea batatas, plant density, plant competition, plant production
}

\begin{abstract}
Changes in leaf distribution of the sweet potato [Ipomoea batatas (L.) Lam.] cultivar Jewel were assessed bi-weekly for 18 weeks at three plant densities $(15,30$, and $45 \mathrm{~cm} \times 96-\mathrm{cm}$ spacing). The distribution of leaves on the branches and the timing at which leaf number stabilized were affected by the plant density. Plant density resulted in significant differences in the number of leaves and percentage of missing leaves during the growing season. Leaf number and total leaf area varied substantially in response to plant density, but individual lamina and petiole lengths and leaf area did not vary. Average petiole and leaf lengths and leaf size increased during the season, with the maximum length and area dependent on the type of branch on which the leaf was formed. Average petiole length per branch and the susceptibility to leaf loss increased with descending branch hierarchy (secondary branch < primary branch < main stem). Leaf losses after the 4th week tended to parallel a progressive increase in petiole length of new leaves, suggesting shading as a primary cause of leaf shedding and the loss of the oldest leaves first.
\end{abstract}

The general morphology of the canopy of the sweet potato has not been adequately studied (Kays, 1985). We have recently shown that the cultivar Jewel produces primary, secondary, and tertiary branches, the number of which is inversely related to plant spacing (Somda and Kays, 1990). In contrast, the number of nodes per branch and average internode length were not greatly affected by plant density, indicating that the 'Jewel' sweet potato adjusts its canopy in relation to the availability of requisites, largely through the control of branch number.

In addition to branch number, length, and orientation, light acquisition and subsequent dry matter production by the plant are also affected by the distribution of leaves on the branches; leaf size, shape, and number, and petiole length. To further characterize the canopy of the sweet potato, we describe herein changes in leaf distribution during the growing season at three plant densities.

\section{Materials and Methods}

'Jewel' sweet potato transplants were planted at three plant densities (15-, 30-, and 45-cm in-row spacing, with $96 \mathrm{~cm}$ between rows) as described by Somda and Kays (1990). Plants were grown in a randomized complete block design with seven replications. Each test row (7.3 m long) was positioned between two border rows of the same spacing.

Individual plants were harvested hi-weekly for 18 weeks, starting on the planting day. The position of each canopy part was determined using a successive ranking. The branches were sequentially severed from the bearing branch and the location of each leaf was identified by the node rank on each branch. Every petiole and lamina on each plant was measured [number, length, area (lamina), and position on the plant]. These measurements were executed sequentially from the base to the apex of the branch.

A Mean Procedure Analysis (SAS, 1982) was used to compile the mean for each variable on each primary and secondary branch and main stem per plant. Data were tested by the General Linear Models procedure and regression analysis.

Received for publication 11 Oct. 1988. The cost of publishing this paper was defrayed in part by the payment of page charges. Under postal regulations, this paper therefore must be hereby marked advertisement solely to indicate this fact.

\section{Results}

Leaf number. The sweet potato plant forms one leaf (petiole and lamina) per node produced. Although the plant could, theoretically, lose only its laminae, no differences were found between petiole and lamina number.

The total number of leaves per plant was greatest in plants growing at $45-\mathrm{cm}$ spacing between 4 and 18 weeks after planting (WAP), when the growth of the plants at the lowest density increased relatively to plants grown at higher densities (Fig. 1A).

The largest proportion of the increase in number of leaves per plant, regardless of spacing, resulted from leaves formed on the branches (both primary and secondary). Plants grown at higher densities had fewer leaves on primary branches than plants grown at lower density (Fig. 1B). Secondary branches accounted for about one-third of the total number of leaves per plant for the higher densities $(15$ and $30 \mathrm{~cm})$, but slightly more than one-half of the total number of leaves per plant for the lowest density $(45 \mathrm{~cm}$ ) (Fig. 1C). Relatively fewer leaves were found on each secondary branch during the season than on each primary branch. The average number of leaves per primary and secondary branch, and main stem, were not affected by plant densities at any harvest date, although they did vary with time (Fig. 1 D-F).

Missing leaves. The percentage of missing leaves per plant was not affected by plant density at any harvest date. It increased from the 4th week through the end of the season, with the final percent of loss in leaves per plant being relatively uniform (i. e., nearly $60 \%$ for all three spacings) (Fig. 2A). The onset of shedding and leaf loss tended to coincide with the formation of both the primary and secondary branches. There was a general increase in percent missing leaves with descending branch hierarchy (secondary branch < primary branch < main stem).

The onset of leaf loss from primary branches did not increase significantly until the development of the secondary branches, and was not affected by plant density. By the end of the growing season, $\approx 60 \%$ of leaves on primary branches per plant were missing, compared to $\approx 35 \%, 42 \%$, and $55 \%$ on secondary branches as spacing increased (Fig. $2 \mathrm{~B}$ and C). The onset of leaf loss from secondary branches did not occur until substantially later in the season, coinciding with development of the tertiary branches. The same relative proportion of missing leaves was found per main stem and individual primary and secondary 


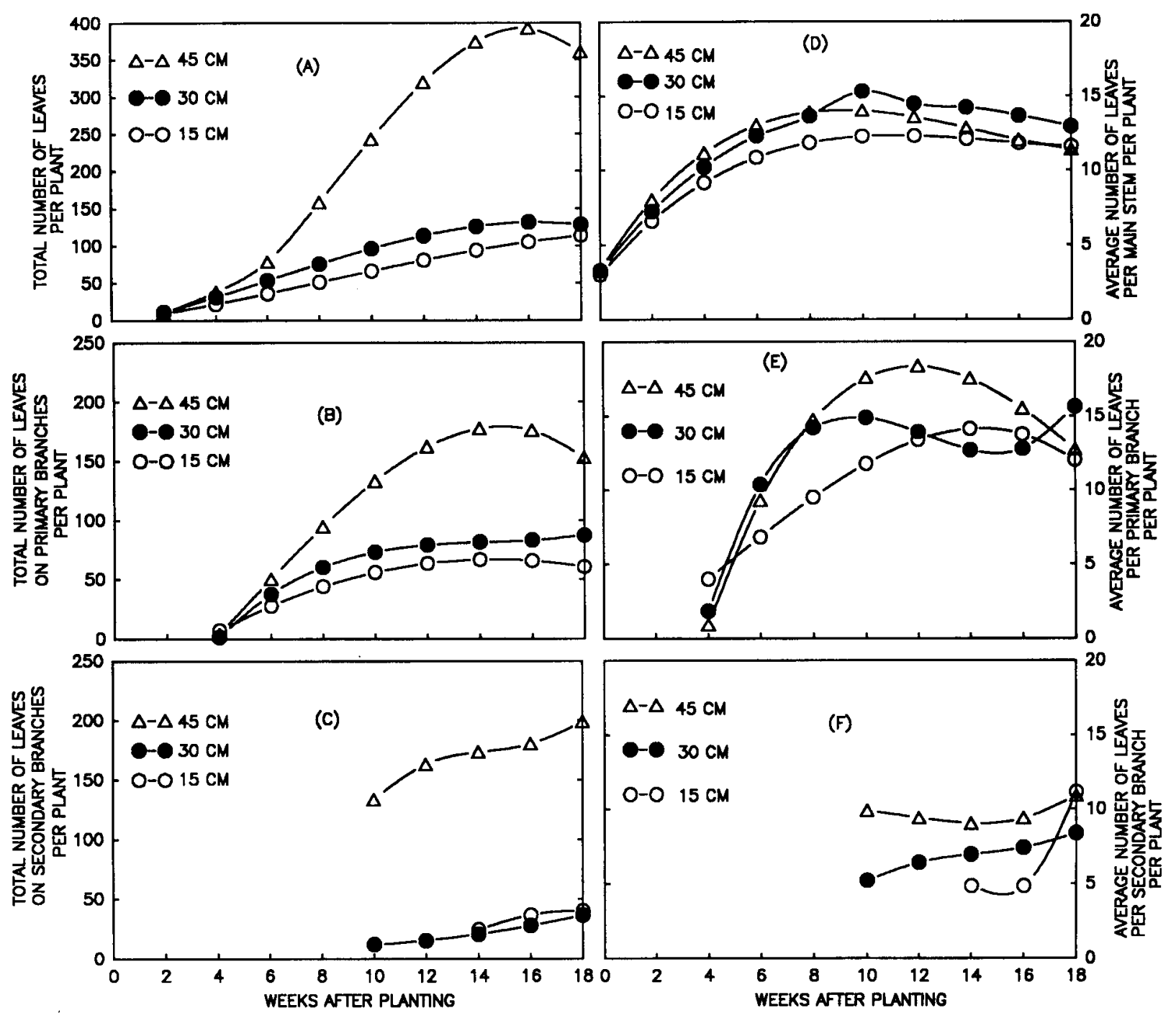

Fig. 1. Effect of plant density $(15,30,45 \times 96 \mathrm{~cm})$ on: $(\mathbf{A})$ total number of leaf blades per plant $\left[15 \mathrm{~cm},-0.04+4.12 \mathrm{X}+0.41 \mathrm{X}^{2}-\right.$ $\left.0.02 \mathrm{X}^{3}\left(R^{2}=0.99\right) ; 30 \mathrm{~cm},-5.08+6.87 \mathrm{X}^{2}-0.04 \mathrm{X}^{3}\left(R^{2}=0.95\right) ; 45 \mathrm{~cm}, 10.27-23.95 \mathrm{X}+7.61 \mathrm{X}^{2}-0.29 \mathrm{X}^{3}\left(R^{2}=0.98\right)\right] ;(\mathrm{B})$ total number of leaf blades on primary branches per plant $\left[15 \mathrm{~cm},-47.83+15.98 \mathrm{X}-0.57 \mathrm{X}^{2}+0.001 \mathrm{X}^{3}\left(R^{2}=0.98\right) ; 30 \mathrm{~cm},-121.53\right.$ $\left.+41.02 \mathrm{X}-2.80 \mathrm{X}^{2}+0.06 \mathrm{X}^{3}\left(R^{2}=0.93\right) ; 45 \mathrm{~cm},-78.23+17.02 \mathrm{X}+1.22 \mathrm{X}^{2}-0.08 \mathrm{X}^{3}\left(R^{2}=0.96\right)\right]$, (C) total number of leaf blades on secondary branches per plant $\left[15 \mathrm{~cm},-86.22-2.10 \mathrm{X}+1.44 \mathrm{X}^{2}-0.05 \mathrm{X}^{3}\left(R^{2}=1.00\right) ; 30 \mathrm{~cm}, 16.97-2.27 \mathrm{X}+0.16 \mathrm{X}^{2}\right.$ $\left.+0.001 \mathrm{X}^{3}\left(R^{2}=0.86\right) ; 45 \mathrm{~cm},-841+205 \mathrm{X}-14 \mathrm{X}^{2}+0.32 \mathrm{X}^{3}\left(R^{2}=0.99\right)\right]$; (D) mean number of leaf blades per main stem per plant ${ }^{z}\left[3.22+2.35 X-0.17 X^{2}+0.003 X^{3}\left(R^{2}=0.84\right)\right] ;(E)$ mean number of leaf blades per primary branch per plant ${ }^{2}[-21.05+7.79 X-$ $\left.0.54 \mathrm{X}^{2}-0.01 \mathrm{X}^{3}\left(R^{2}=0.89\right)\right]$; and $(\mathbf{F})$ mean number of leaf blades per secondary branch per plant at 2-week intervals throughout the growing season.

zPooled regression equation for all spacings

branches (Fig. 2 D-F). The percentage of main stem leaf loss varied only to a limited extent with plant density and was about $75 \%$ for all three spacings $18 \mathrm{WAP}$, relative to $\approx 160 \%$ and $40 \%$ of missing leaves per individual primary and secondary branches, respectively.

Petiole length. During the early stages of development of the canopy of the sweet potato, petiole length was at its minimum, regardless of plant density (Fig. 3A). Toward the middle and the latter part of the growing season, average petiole length on primary branches increased substantially at all plant densities (Fig. 3 B and C), but increased minimally or not at all on secondary branches (Fig. ID). On an individual branch basis, petioles found at the apex were still elongating, while those at the middle portion were at maximal length. The basipetal and oldest petioles were relatively shorter than petioles produced later by the plant (Fig. 4). Occasionally, a short petiole was found within a series of long petioles. Typically, this type of petiole was adjacent to an internode that also was short and supported a small leaf lamina.

Leaf lamina length. The average leaf lamina length per plant and main stem increased until 14 to $16 \mathrm{WAP}$, regardless of plant density (Fig. 5 A and B). Toward the latter part of the growing season, average length of leaf lamina per plant and main stem declined, whereas the leaf lamina length on primary and secondary branches remained relatively constant (Fig. 5 AD). The average leaf lamina length decreased with increasing branch hierarchy (i.e., main stem $>$ primary branch $>$ secondary branch).

Individual leaf area. The average leaf area increased steadily (with decreasing plant density) until 14 WAP (Fig. SE). During 


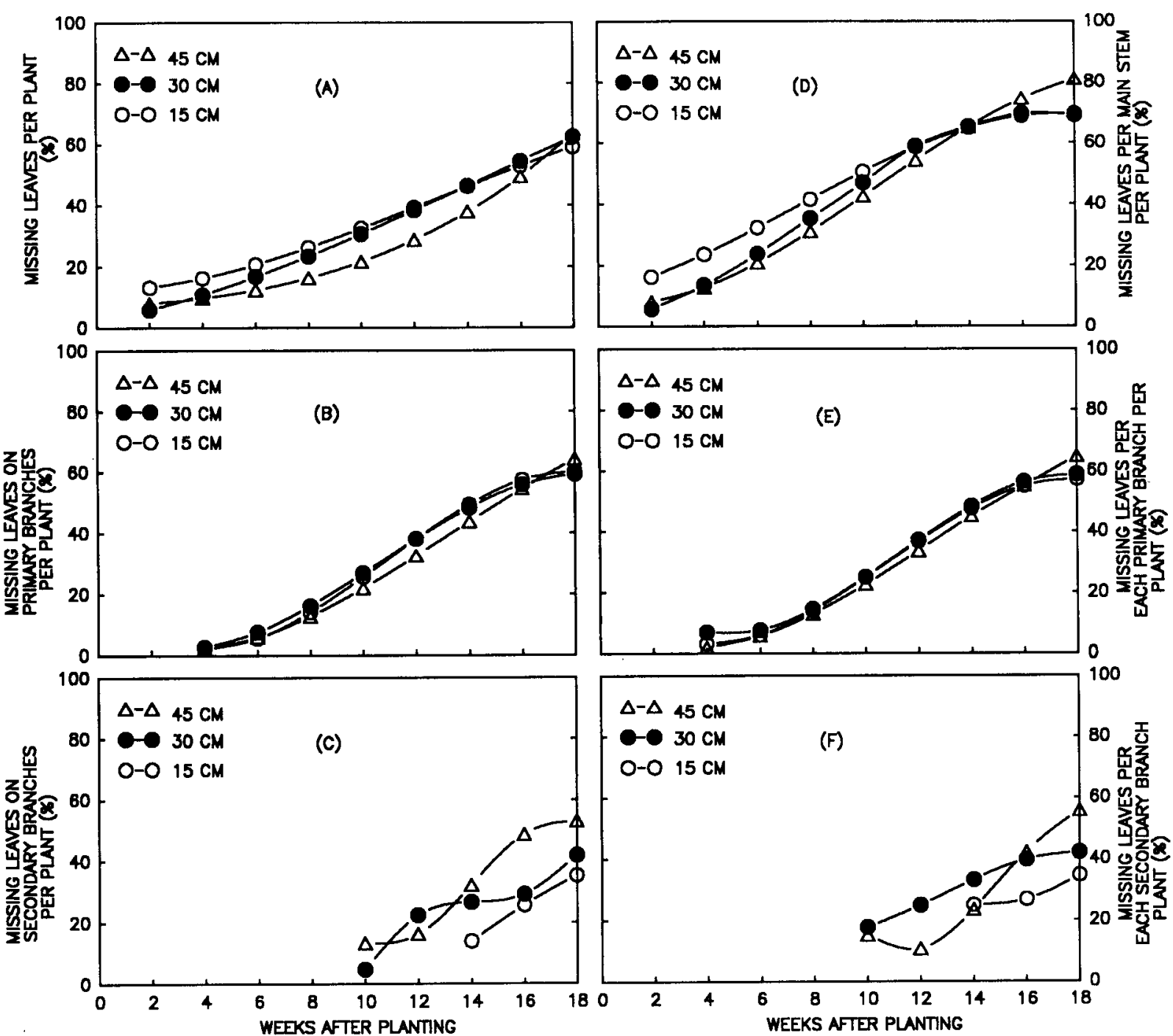

Fig. 2. Effect of plant density $(15,30,45 \times 96 \mathrm{~cm})$ on: $(\mathbf{A})$ percent of missing leaves per plant ${ }^{z}\left[7.07+0.67 \mathrm{X}+0.16 \mathrm{X}^{2}-0.002 \mathrm{X}^{3}\left(R^{2}\right.\right.$ $=0.92)]$; (B) on primary branches per plant ${ }^{2}\left[12.13-6.22 \mathrm{X}+1.06 \mathrm{X}^{2}-0.03 \mathrm{X}^{3}\left(R^{2}=0.98\right)\right]$; (C) on secondary branches per plant ${ }^{2}\left[-100+20 \mathrm{X}-1.23 \mathrm{X}^{2}+0.03 \mathrm{X}^{3}\left(R^{2}=0.84\right)\right] ;(\mathrm{D})$ per main stem per plant ${ }^{2}\left[6.75+0.58 \mathrm{X}+0.55 \mathrm{X}^{2}-0.02 \mathrm{X}^{3}\left[R^{2}=0.95\right)\right] ;(\mathrm{E})$ per individual primary branch per plant ${ }^{2}\left[21.23-8.90 \mathrm{X}+1.30 \mathrm{X}^{2}-0.04 \mathrm{X}^{3}\left(R^{2}=0.98\right)\right]$; and $(\mathrm{F})$ per individual secondary branch per plant, ${ }^{z}\left[253-55 \mathrm{X}+4.08 \mathrm{X}^{2}-0.09^{3}\left(R^{2}=0.83\right)\right]$ at 2 -week intervals throughout the growing season.

${ }^{\mathrm{x}}$ Pooled regression equation for all spacings.

the latter part of the season, the average leaf area declined slightly at all plant densities. Similar variations were found for the average leaf area on primary and secondary branches and on the main stem (Fig. 5 F-H). All plants had larger leaf areas toward the inner part of the canopy (i.e., main stem > primary > secondary branch). Within the branch-type, however, there were no significant differences due to plant densities.

Leaf area per plant. Integrating number and size of leaves per plant allows analysis of changes in total leaf area with time, plant density, and within individual components of a plant (e.g., branch type). The total leaf area per plant increased progressively until the 16th WAP, the rate of which depended on plant density (Fig. 6A). Subsequent changes varied between plant density until the final harvest. The major increase and differences in total leaf area per plant occurred from 4 to 16 WAP, when the number of leaves of plants at the lowest density increased relatively to plants grown at the higher densities.

The largest proportion of increase in the leaf area per plant, regardless of plant densities, resulted from leaves formed on primary and secondary branches. The average total leaf area on primary branches per plant increased with time until 12 WAP (Fig. 6B). Subsequent changes varied between plant density until final harvest.

The secondary branches accounted for about one-third of the total leaf area per plant for the higher plant densities (15 and $30 \mathrm{~cm}$ ), but slightly more than one-half of the total leaf area per plant for the lowest density $(45 \mathrm{~cm})$ at the end of the season (Fig. 6C). The average leaf area on main stem increased steadily until final harvest at the highest density $(15 \mathrm{~cm})$, but declined from 14 to 18 WAP at the lower densities (30 and $45 \mathrm{~cm}$ ) (Fig. 6D). Plants grown at higher densities $(15$ and $30 \mathrm{~cm})$ had lower average leaf areas per individual primary and secondary branch than plants grown at the lower density $(45 \mathrm{~cm})$ (Fig. $6 \mathrm{E}$ and F). These differences were not only due to the number of leaves, but also due to the size of the individual leaves and number of leaves that were shed from the plant. 


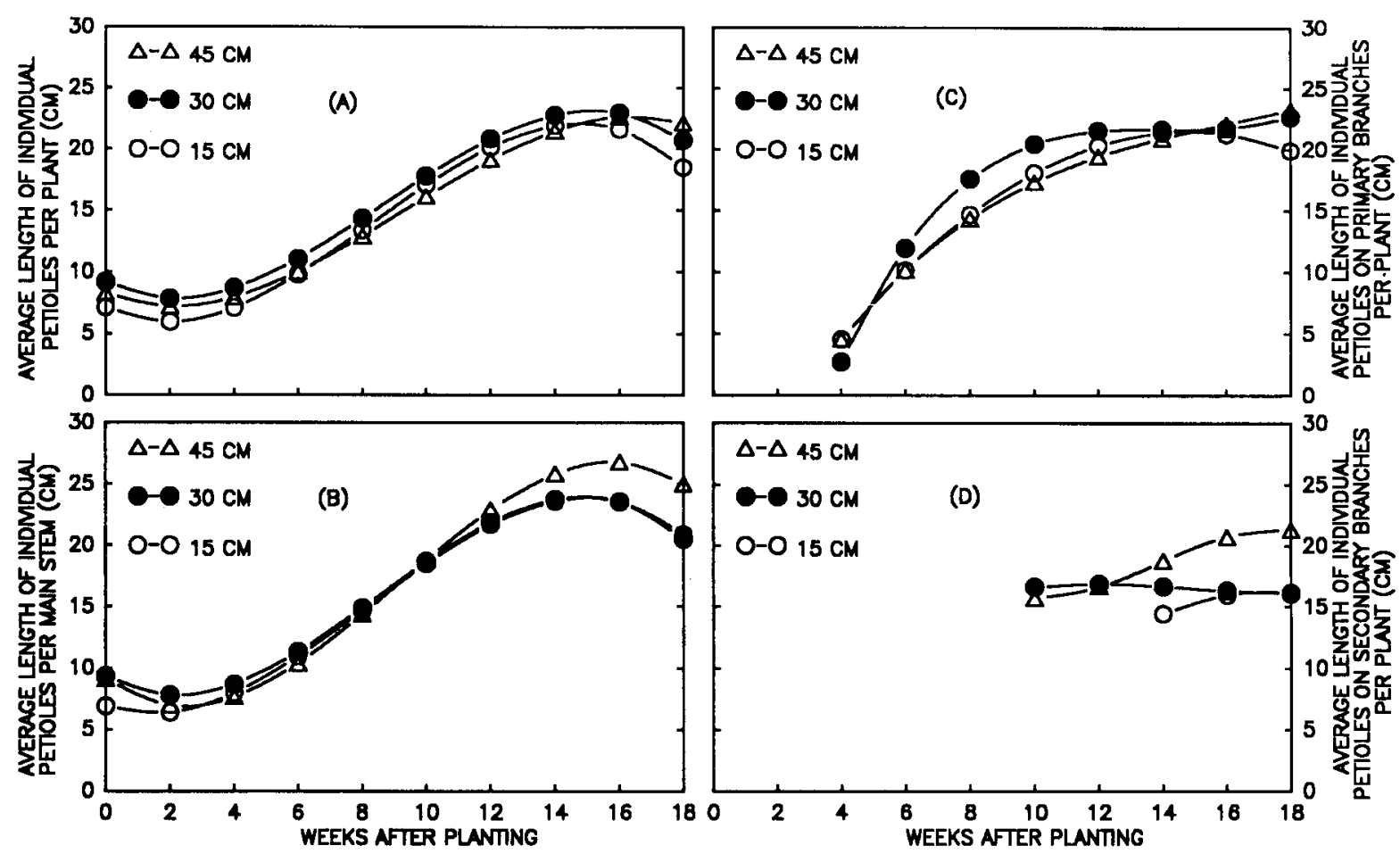

Fig. 3. Effect of plant density $(15,30,45 \times 96 \mathrm{~cm})$ on mean petiole length $(\mathrm{A})$ per plant ${ }^{2}\left[8.19-1.23 \mathrm{X}+0.34 \mathrm{X}^{2}-0.01 \mathrm{X}^{3}\left(R^{2}=\right.\right.$ $0.98)]$; (B) per main stem per plant ${ }^{2}\left[8.44-1.45 \mathrm{X}+0.40 \mathrm{X}^{2}-0.02 \mathrm{X}^{3}\left(R^{2}=0.96\right)\right]$; (C) per primary branch per plant ${ }^{z}[-17.28+$ $\left.6.77 \mathrm{X}-0.40 \mathrm{X}^{2}+0.01 \mathrm{X}^{3}\left(R^{2}=0.96\right)\right]$; and $(\mathrm{D})$ per secondary branch per plant ${ }^{2}\left[25.10-2.16 \mathrm{X}+0.16 \mathrm{X}^{2}-0.004 \mathrm{X}^{3}\left(R^{2}=0.30\right)\right]$ at 2 -week intervals throughout the growing season.

${ }^{2}$ Pooled regression equation for all spacings.

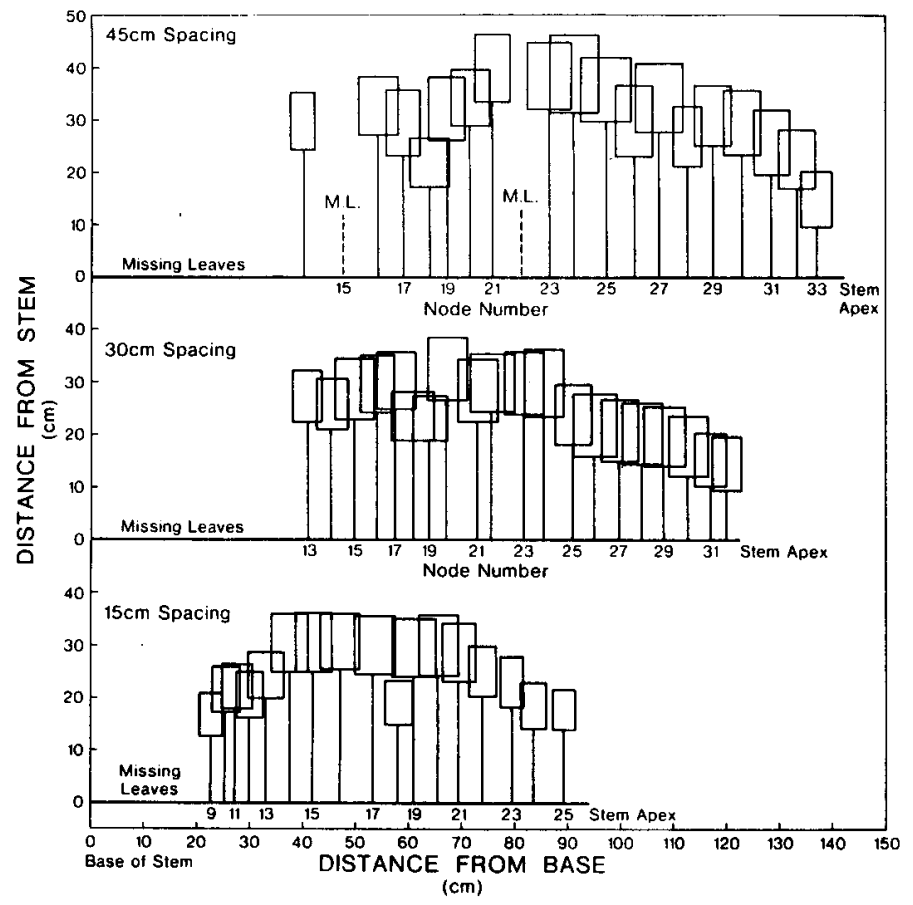

Fig. 4. Leaf distribution on representative branches of plants grown at three in-row spacings $(15,30,45 \times 96 \mathrm{~cm}) 176$ weeks after planting.

\section{Discussion}

'Jewel' sweet potato plants grew rapidly and largely horizontally. Canopy development, as reflected by leaf number and leaf area per plant, increased most rapidly during the period from 6 to 12 WAP. Regression analysis on the canopy components, using general linear models, revealed that the changes in leaf characteristics as the season progressed were cubic. Both leaf number and leaf area per plant tended to stabilize during the latter part of the growing season. Plant density and length of time after planting had a significant effect on both characteristics. While leaf size increased in all plant densities during the early part of the growing season, differences in leaf area per plant between densities could not be attributed to variation in leaf size; rather, the variation was due to differences in leaf number.

Leaf number per plant depends primarily on the number of growing points (branches), rate of growth, and leaf losses. Plateauing of leaf number and leaf area per plant would indicate either a cessation of photosynthate allocation into new canopy growth or an increase in leaf loss commensurate with the rate of new leaf development. We found (Somda and Kays, 1990) that the number of nodes per plant increased as the season progressed, indicating that leaf loss appeared to maintain a more or less stable leaf density within the canopy from mid-season until harvest (126 days). This finding is supported by leaf area index (LAI) data of $\mathrm{Li}$ and Yen (1988), which showed a peaking of LAI at 90 days, only a slight decline at 120 days, and then a greater decline by 180 days. Thus, there was a progressive increase in the percentage of leaves shed of the total formed as the season progressed.

Leaf losses during the growing season can be mediated by physical removal of leaves (e.g., herbivory) and/or leaf senescence induced by diseases, nutrient deficiency, low light, or other causes. The absence of differences in the percent leaf loss per plant, even though plant size varied greatly between densities, would suggest that losses were largely the result of in- 

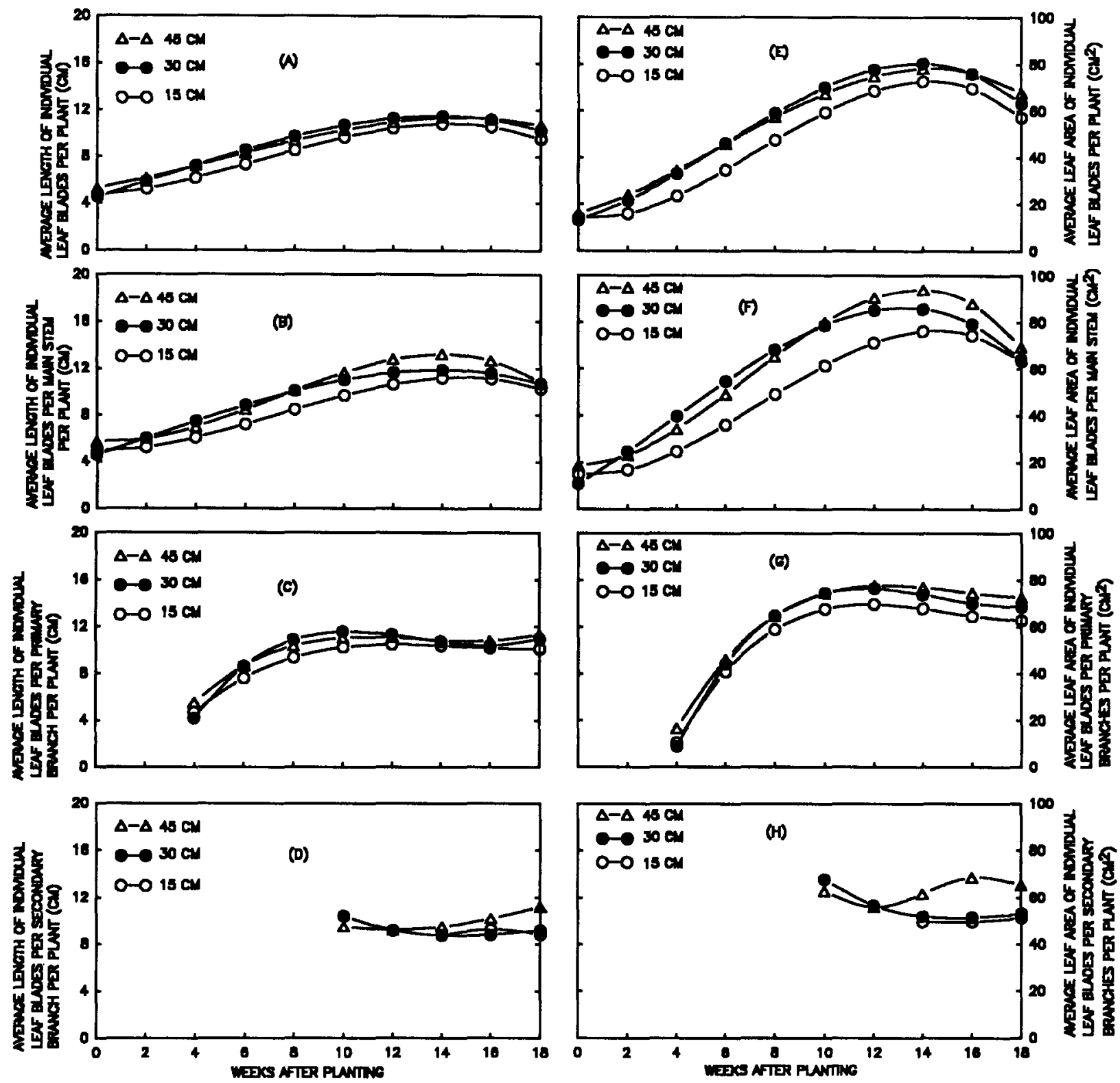

Fig. 5. Effect of plant density $(15,30,45 \times 96 \mathrm{~cm})$ on average length of individual leaf blades $(\mathbf{A})$ per plant ${ }^{z}\left[4.82+0.39 X+0.04 X^{2}-\right.$ $\left.0.002 \mathrm{X}^{3}\left(R^{2}=0.95\right)\right] ;(\mathbf{B})$ per main stem per plant ${ }^{2}\left[5.06+0.20 \mathrm{X}+0.08 \mathrm{X}^{2}-0.004 \mathrm{X}^{3}\left(R^{2}=0.92\right)\right]$; (C) on primary branches per plant $z\left[-8.78+4.69 \mathrm{X}-0.36 \mathrm{X}^{2}+0.01 \mathrm{X}^{3}\left(R^{2}=0.93\right)\right]$; (D) on secondary branches per plant ${ }^{2}\left[35.48-5.13 \mathrm{X}+0.32 \mathrm{X}^{2}-0.01 \mathrm{X}^{3}\left(\mathbf{R}^{2}=\right.\right.$ $0.46)]$; and on average leaf area of individual leaf blades $(\mathbf{E})$ per plant ${ }^{2}\left[14.44+1.76 \mathrm{X}+0.69 \mathrm{X}^{2}-0.04 \mathrm{X}^{3}\left(R^{2}=0.96\right)\right] ;(\mathbf{F})$ per main stem per plant ${ }^{2}\left[14.70+1.90 \mathrm{X}+0.83 \mathrm{X}^{2}-0.04 \mathrm{X}^{3}\left(R^{2}=0.91\right)\right] ;(\mathbf{G})$ on primary branches per plant ${ }^{2}\left[-99.91+37.47 \mathrm{X}-2.60 \mathrm{X}^{2}+\right.$ $\left.0.06 \mathrm{X}^{3}\left(R^{2}=0.95\right)\right]$; and $(\mathbf{H})$ on secondary branches per plant ${ }^{\mathrm{z}}\left[390-67 \mathrm{X}+4.45 \mathrm{X}^{2}-0.10 \mathrm{X}^{3}\left(R^{2}=0.46\right)\right]$ at 2 -week intervals throughout the growing season.

zPooled regression equation for all spacings.

adequate light within the canopy. We found a progressive increase in petiole length as the season progressed, indicating that the height of the canopy was increasing. This elevation in canopy height resulted in the older leaves, which were on shorter petioles, being placed at a progressively lower position in the light reception hierarchy as the season progressed. Hence, leaves on shorter petioles, found toward the lower portion of individual branches, were lost (Fig. 4). The amount of leaf loss was remarkably high; i.e., $58 \%$ to $60 \%$ of the leaves formed during the growing season. To obtain an estimate of the consistency of this response, plants grown at a $30 \times 96-\mathrm{cm}$ spacing were harvested the following season and the percent leaf loss determined. At corresponding dates from planting, the percentage of missing leaves consistently differed only $1 \%$ to $2 \%$ (e.g., at 14 weeks, $54 \%$ vs. $53 \%$ ).

Leaf losses, although quite large, typically go unnoticed in sweet potato canopies. This appears to be due to: a) the position of the leaves that are shed within the canopy; b) the presence of a full canopy covering the entire soil surface; c) the recycling of a significant portion of the dry matter out of the senescing leaves back into the parent plant (S. J. K., unpublished data); and d) the rapid decomposition of the remainder of the leaf after shedding.

Branching hierarchy had a significant effect on several morphological characteristics of the canopy (Somda and Kays, 1990). The primary effects of branching hierarchy appeared to be due 

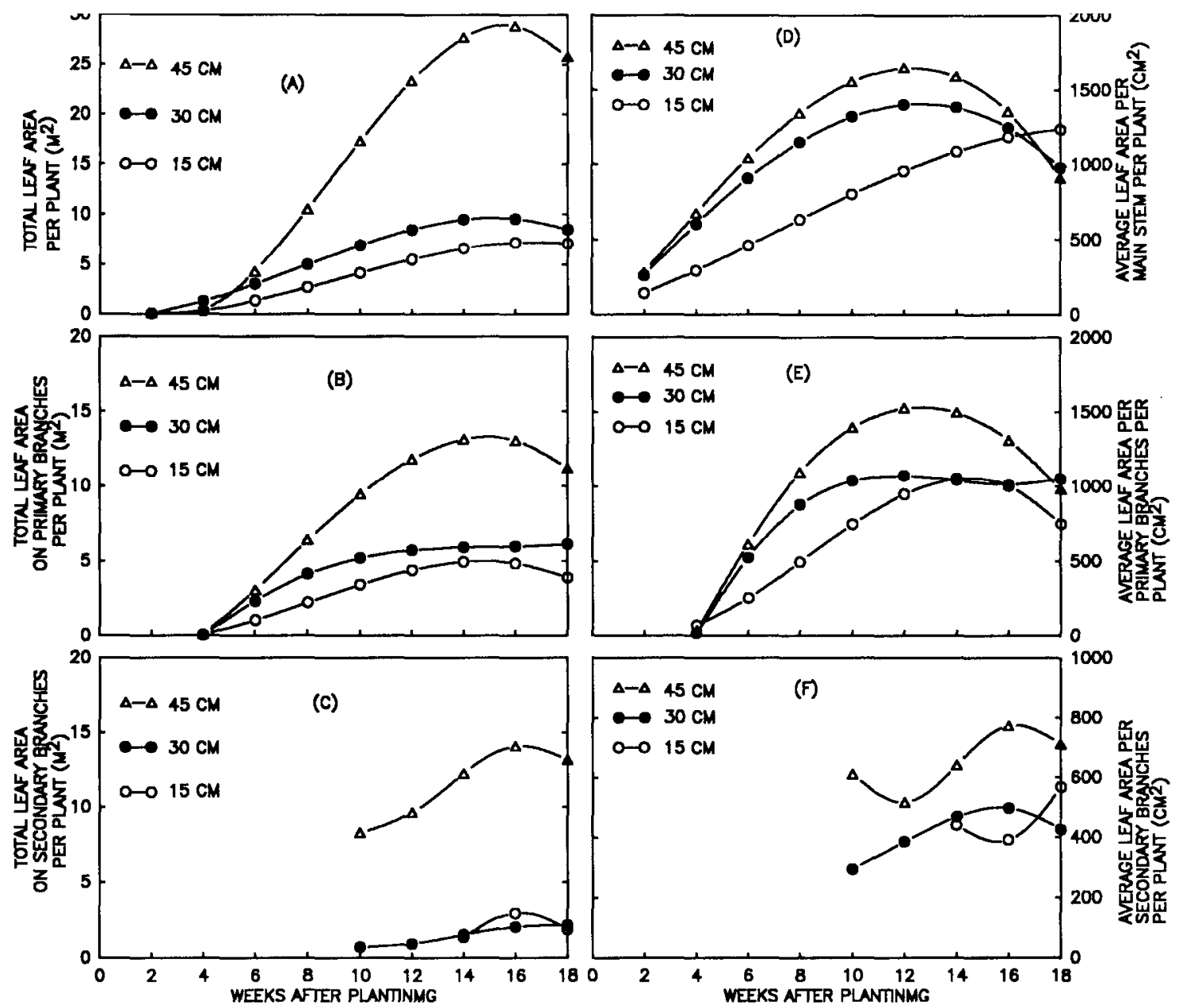

Fig. 6. Effect of plant density $(15,30,45 \times 9 \mathrm{~cm})$ on total leaf area (A) per plant $\left[15 \mathrm{~cm}, 149.66-351.49 \mathrm{X}+117.86 \mathrm{X}^{2}-4.28 \mathrm{X}^{3}\left(R^{2}\right.\right.$ $\left.=0.99) ; 30 \mathrm{~cm},-335.63-33.12 \mathrm{X}+134.19 \mathrm{X}^{2}-5.84 \mathrm{X}^{3}\left(R^{2}=0.96\right) ; 45 \mathrm{~cm}, 1121-2632 \mathrm{X}+678 \mathrm{X}^{2}-25 \mathrm{X}^{2}\left(R^{2}=0.98\right)\right] ;(\mathrm{B})$ on primary branches per plant $\left[15 \mathrm{~cm},-322.17-275.91 \mathrm{X}+110.73 \mathrm{X}^{2}-4.58 \mathrm{X}^{2}\left(R^{2}=0.99\right) ; 30 \mathrm{~cm},-9584+2996 \mathrm{X}-194 \mathrm{X}^{2}+\right.$ $\left.4.23 \mathrm{X}^{3}\left(R^{2}=0.93\right) ; 45 \mathrm{~cm},-5113+751 \mathrm{X}+148 \mathrm{X}^{2}-7.73 \mathrm{X}^{3}\left(R^{2}=0.91\right)\right] ;(\mathrm{C})$ on secondary branches per plant [15 $\mathrm{cm},-26792-$ $172 \mathrm{X}+358 \mathrm{X}^{2}-14.46 \mathrm{X}^{3}\left(R^{2}=1.00\right) ; 30 \mathrm{~cm}, 18378-4303 \mathrm{X}+334 \mathrm{X}^{2}-8.08 \mathrm{X}^{3}\left(R^{2}=0.84\right) ; 45 \mathrm{~cm}, 90359-20665 \mathrm{X}+1663 \mathrm{X}^{2}$ $\left.-41.86 \mathrm{X}^{3}\left(R^{2}=0.97\right)\right]$; and on average leaf area $(\mathrm{D})$ per main stem per plant $\left[15 \mathrm{~cm}, 16.12+54.75 \mathrm{X}+4.49 \mathrm{X}^{2}-0.21 \mathrm{X}^{3}\left(R^{2}=0.96\right)\right.$; $\left.30 \mathrm{~cm},-116+193 \mathrm{X}-1.82 \mathrm{X}^{2}-0.30 \mathrm{X}^{3}\left(R^{2}=0.84\right) ; 45 \mathrm{~cm},-122+196 \mathrm{X}+3.28 \mathrm{X}^{2}-0.61 \mathrm{X}^{3}\left(R^{2}=0.90\right)\right] ;(\mathrm{E})$ per primary branch per plant $\left[15 \mathrm{~cm}, 96.79-98.78 \mathrm{X}+27.47 \mathrm{X}^{2}-1.12 \mathrm{X}^{3}\left(R^{2}=0.99\right) ; 30 \mathrm{~cm},-2317+761 \mathrm{X}-55.85 \mathrm{X}^{2}+1.33 \mathrm{X}^{3}\left(R^{2}=0.91\right)\right.$; $\left.45 \mathrm{~cm},-1980+585 \mathrm{X}-26.42 \mathrm{X}^{2}+0.17 \mathrm{X}^{3}\left(R^{2}=0.96\right)\right]$; and $(\mathbf{F})$ per secondary branch per plant $\left[15 \mathrm{~cm}, 2449+11.08 \mathrm{X}-27.19 \mathrm{X}^{2}\right.$ $+1.15 \mathrm{X}^{3}\left(R^{2}=1.00\right) ; 30 \mathrm{~cm}, 1300-337 \mathrm{X}+33.09 \mathrm{X}^{2}-0.95 \mathrm{X}^{3}\left(R^{2}=0.99\right) ; 45 \mathrm{~cm}, 1562-2485 \mathrm{X}+182 \mathrm{X}^{2}-4.30 \mathrm{X}^{3}\left(R^{2}=\right.$ $0.99)]$ at 2-week intervals throughout the growing season.

to timing. The main stem was present at planting, with the initial primary branches being formed between the 2nd and 4th WAP. Secondary branches, however, did not begin to form until the 8th to 14th week, depending on plant density. A few tertiary branches were formed sporadically thereafter. As a consequence, early in the growing season, there were significant differences due to branching order that were no longer significant by the end of the season; e.g., average number of leaves per branch type, and petiole and leaf lamina lengths. Leaf characteristics that differed significantly due to branch hierarchy by the end of the growing season included total number and area of leaves, average leaf area, and leaf losses. Total leaf number and leaf area was higher on primary branches $(15-$ and $30-\mathrm{cm}$ spacing) than on secondary ones. This was not the case at the 45-cm spacing, where the plants were substantially larger and secondary branches made up a correspondingly greater percentage of the entire canopy. Both primary and secondary branches had greater total leaf areas than the main stem (Fig. $6 \mathrm{~B}$ and $\mathrm{C}$ vs. D). Average leaf area on branches did not differ substantially between main stem and primary branches by the end of the season; however, both were substantially higher than secondary branches.

The sweet potato has a rapidly growing, highly plastic canopy that quickly covers the exposed surface of the soil. The plant adjusts its canopy size largely by controlling branch formation. Once neighboring canopies merge, the allocation of resources into new leaves and branches does not cease; however, leaf area index (LAI) does not increase unabated. Instead, leaf area is maintained within a relatively consistent range during much of the growing season. Losses in LAI during the latter part of the season found by some workers (e.g., Bourke, 1984; Li and Yen, 1988) may be due to decline in new branch and leaf formation relative to leaf losses and possible recycling of carbon from the canopy into the storage organs late in the season.

Significant leaf shedding occurs in the canopy of the sweet potato. The importance of the leaf shedding phenomenon rela- 
tive to the net yield of harvestable product and its possible adaptive advantage remain to be ascertained.

\section{Literature Cited}

Bourke, M. 1984. Growth analysis of four sweet potato (Ipomoea batatas) cultivars in Papua New Guinea. Trop. Agr. (Trinidad) 61:177181.

Kays, S.J. 1985. The physiology of yield in the sweet potato, p. 79-
132. In: J.C. Bouwkamp (ed.). Sweet potato products: A natural resource for the tropics. CRC Press, Boca Raton, Fla.

Li, L. and F. Yen. 1988. The effect of cultural practices on dry matter production and partition in sweet potato (Ipomoea batatas) cultivars. J. Agr. Assn. Chem. 141:47-61.

SAS Institute. 1982. SAS user's guide: Basics. SAS Institute, Inc., Cary, N.C.

Somda, Z.C. and S.J. Kays. 1990. Sweet potato canopy architecture: Branching pattern. J. Amer. Soc. Hort. Sci. 115(1):33-38. 